\title{
Securing a Future for China's Wild Plant Resources
}

\author{
WEIGUO SANG, KEPING MA, AND JAN C. AXMACHER
}

\begin{abstract}
China harbors one of the most species-rich floras in the world. This plant diversity is currently severely threatened by high levels of habitat degradation and unsustainable resource extraction, the country's exceptionally fast economic growth, an uncontrolled increase in tourism, invasive species, and climate change. Furthermore, China's current system of protected areas is ineffective at conserving the country's plant resources, with low levels of enforcement and only a few small reserves located in both the most phytodiverse regions and in areas facing the highest anthropogenic pressure. Seven strategic steps are required in order to secure a future for China's wild plants, including surveys to establish current species distributions and threat levels, the creation of an effective protected-area system focused on quality rather than quantity, resettlement of parts of the scattered rural population, control of the illegal export trade and invasive species, and a streamlining of administrative responsibilities and capacity building in conservation.
\end{abstract}

Keywords: Anthropogenic threats, overexploitation, priority conflict, protected-area management

$\mathbf{T}^{\mathrm{n}}$ he world's failure to achieve the $\mathbf{2 0 1 0}$ target of significantly reduced global biodiversity losses (Butchart et al. 2010) raises the crucial question of how the future global wealth in biological resources can be successfully safeguarded. In this essay, we summarize the situation facing China's highly diverse flora and outline the strategic steps necessary to ensure the effective protection of its wild plant resources.

Including Taiwan, China harbors nearly 33,000 vascular plant species (López-Pujol et al. 2006). It is one of the most phytodiverse countries on our planet and a key source area for global agricultural plants (Harkness 1998, Purugganan and Fuller 2009). Furthermore, about half of China's seed plant species are endemic (Ying and Zhang 1994, SEPA 1998) and 9300 species are used in traditional Chinese medicine (Wu X 1992). Plant resources will remain of supreme importance in supporting China's sustainable future development by securing its food security and social stability. Furthermore, these resources are crucial for the global community as a source of medicinal substances and of new crop varieties resistant to pests, crop diseases, and changing climatic conditions.

\section{Habitat degradation and resource exploitation}

The natural vegetation in China has been exploited and depleted for many centuries; vast areas of forest and steppe have been transformed for agricultural use (Rozelle et al. 1997, Li W 2004, Xu et al. 2009). The resulting environmental degradation has led to severe soil erosion, landslides, and dust storms affecting many large cities (López-Pujol et al. 2006), which has in turn stimulated large-scale reforestation projects and a recent ban on logging in natural forests ( $\mathrm{Li} \mathrm{W}$ 2004). Nonetheless, reforested areas are often species poor and frequently contain nonnative species (Stone 2009), or they are established in fragile steppe ecosystems (Williams 2005, Cao et al. 2010). These factors strongly limit the areas' value in safeguarding China's phytodiversity (López-Pujol et al. 2006).

Most of China's remaining "natural" forests are also secondary ecosystems, supporting reduced levels of plant diversity (Li W 2004), with the last pristine forest remnants limited to remote areas in China's northeast, Inner Mongolia, the Brahmaputra Canyon, and alpine areas in the southwest. Even the natural forests are highly threatened, despite their strict legal protection (Wang et al. 2007). As the great wealth generated by China's rapid economic growth is concentrated in urban areas, poverty prevails in many rural parts of the country. The rural population living in scattered settlements strongly relies on the extraction of natural resources in the vicinity of their villages for survival, which commonly results in their being tempted to log and collect plants within protected areas (López-Pujol et al. 2006).

The exploitation of timber, but also of other wild plant resources, poses a major threat to the long-term survival of the affected species. Most species used in traditional Chinese medicine, for example, are exclusively collected in the wild, and many medicinal plant species have suffered severe reductions in populations and distribution ranges (Zhou and Jiang 2004, López-Pujol et al. 2006, Yu 2010). Meanwhile, the government's recent bans on the collection of rare and endangered species remain largely unenforced. 


\section{Pressure from economic development}

China's economic development itself creates substantial problems for the future safeguarding of Chinese plant resources, because local governments strongly prioritize short-term economic growth over the long-term protection of natural resources (Cao et al. 2010, Yu 2010). Mining, wetland reclamation, agricultural intensification, and the rapid spread of urban areas are all fuelling environmental degradation through habitat destruction, replacement of native vegetation with exotic species, and severe pollution of the air and water (Liu and Diamond 2005, López-Pujol et al. 2006). China's urbanization level, for example, rose from $13 \%$ in 1952 to $44 \%$ in 2008 (Normile 2008), leading to substantial losses of seminatural habitats in suburban areas. This transformation of the suburban landscape alters the species richness and the composition of the affected regions, with strong implications, especially for plant species conservation (Peng et al. 2004).

A more subtle threat created by China's new wealth is the vast increase in tourism, with visitor numbers in the last remaining pristine areas growing dramatically in recent years (Han and Ren 2001, Liu et al. 2003). Because these areas also harbor some of China's most threatened plant resources, conflicts between tourism and nature conservation are commonplace (SEPA 2007), with tourism generally being favored by the local governments. The combined effects of the development of tourism infrastructure and the trampling of and collection of natural resources for sale to tourists therefore pose further important risks for rare and threatened plant species (López-Pujol et al. 2006). As Han and Ren (2001) pointed out, a possible solution to this inherent threat is the development of sustainable ecotourism. However, such a move would require substantial improvements in staff training and resource provision, as well as a clear set of guidelines for the sustainable management and conservation of the natural resources within protected areas.

\section{China's protected areas}

The threats facing pristine habitats despite their strict legal protection are indicative of further significant shortcomings in China's protected-area system. With the exception of post1992 national nature reserves, basic data on, for example, the number of species inhabiting protected areas, their population sizes, and their distribution is widely lacking. Full inventories of plant resources have been carried out in less than half of China's 2395 nature reserves (SEPA 2007), and the widespread lack of basic knowledge of plant resources makes effective conservation planning virtually impossible. About a third of reserve managers were unsure about even the exact area and extent of their reserves (SEPA 2007), with many parks existing only on paper (Jim and Xu 2004). This problem reflects the strong emphasis on creating new reserves, rather than on securing the effective management and resource conservation of existing protected areas. Currently, $40 \%$ of all nature reserves lack an administration, whereas $25 \%$ are without professional management staff (Han 2000, Han and Ren 2001). These problems are augmented by poor working conditions, low salaries, and a lack of clear management and conservation focus (Mittermeier et al. 2005, SEPA 2007). Less strictly protected areas, such as scenic spots and forest and wetland parks, face similar problems, which are often further amplified by an even stronger emphasis on the development of tourism at the expense of biological resources.

The spatial distribution of protected areas highlights further problems. The geographic distribution of plant species and endemics in China is highly uneven, with Yunnan and Sichuan Provinces harboring by far the greatest phytodiversity (figures 1 and 2). In contrast, the largest protected areas are located in the underpopulated western areas (figure 2; CantúSalazar and Gaston 2010). The four largest nature reserves, in the Tibet (Xizang), Qinghai, and Xinjiang Provinces, already account for $60 \%$ of the total area protected in national nature

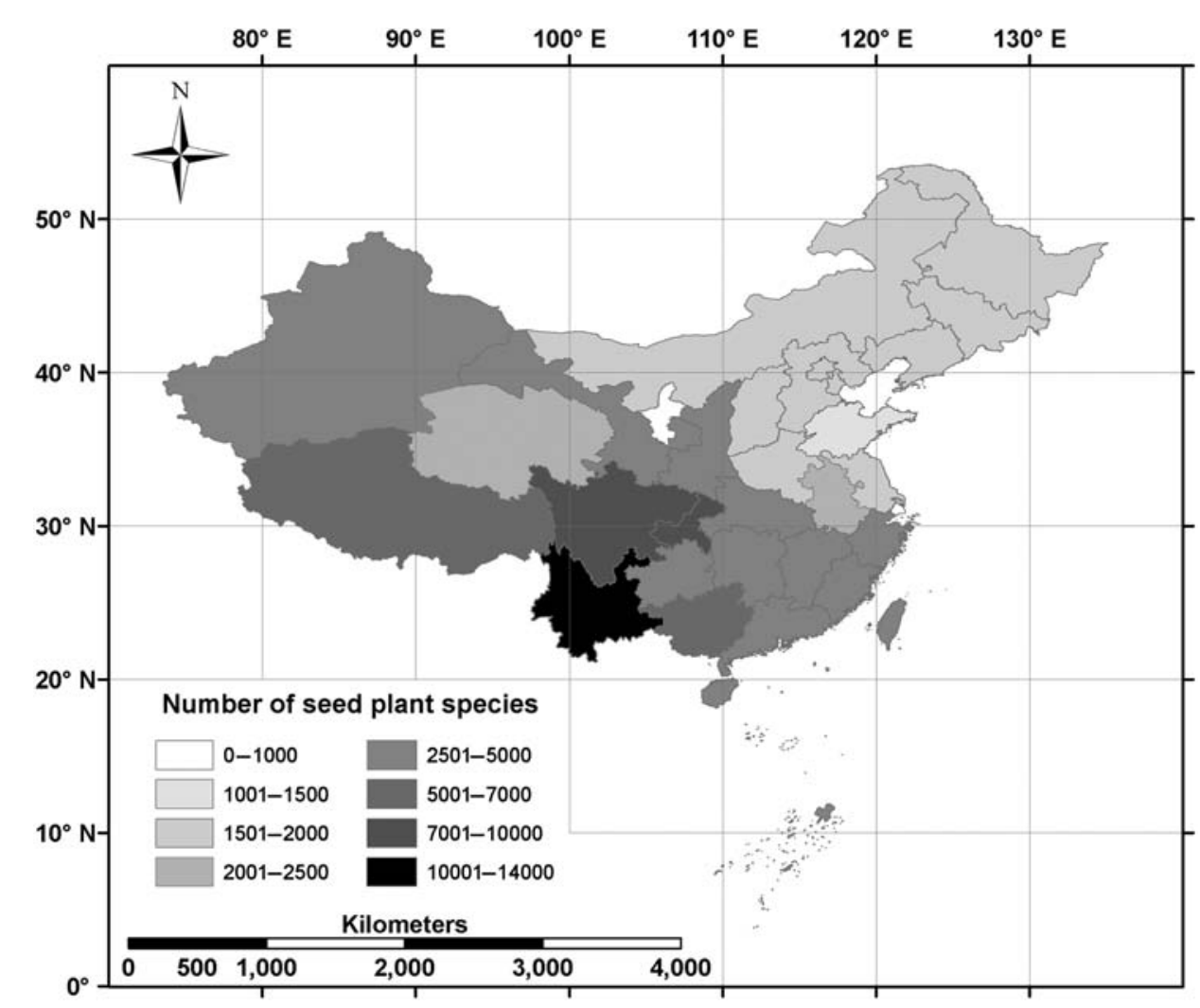

Figure 1. Number of seed plant species in China's provinces and autonomous regions. 


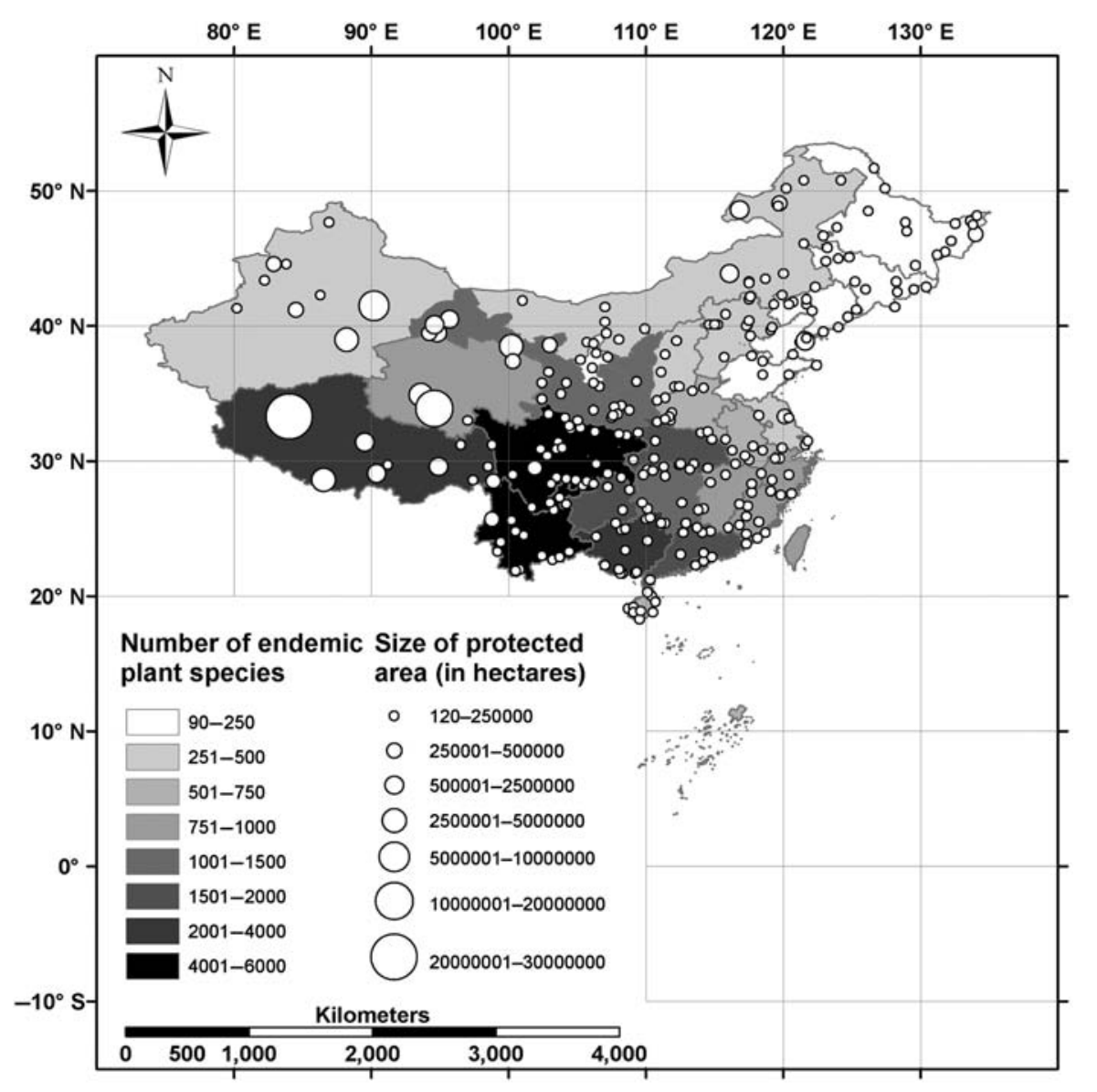

Figure 2. Endemic plant species richness and distribution of state-level protected areas in China's provinces and autonomous regions.

reserves. The combined size of all reserves in the 12 western provinces and regions represents $85 \%$, whereas the nature reserves in the Yunnan and Sichuan Provinces account for only 3.4\% of China's total protected land area. Protected areas in the eastern regions, China's agricultural and economic heartland, are also small and scattered, whereas the species in this area face the greatest pressure from China's economic development and worsening pollution.

In addition, the reserve network reflects a strong bias toward iconic species and habitats. Of the 120 habitat types regarded as conservation priority habitats in China, 20 do not fall within any of the national nature reserves (SEPA 2007). Furthermore, in excess of 50 nature reserves have been created for the in situ conservation of the giant panda, whereas many endemic and threatened plant species are located outside any protected area (Zhang Y-B and Ma 2008). This is especially problematic for plant species with small distribution ranges, such as many orchids, and for wild populations of agricultural plants, which are often highly fragmented and rare (Hu et al. 2009).

\section{Threats of invasive species and climate change}

Two emerging threats will also have to be considered in securing the future of Chinese plant resources. First, as

\section{Seven strategic steps}

China's international trade started to flourish and urbanization rates increased, invasive species became established and rapidly spread throughout the country (Ding et al. 2008). These species severely affect the structure and functioning of ecosystems, potentially driving already decimated populations of rare plant species even closer to extinction (Li M and Xu 2005). The estimated current annual economic damage caused by invasive species already reaches about US $\$ 14.5$ billion, or $1.36 \%$ of China's gross domestic product (Weber and Li 2008). It must be assumed that this figure will increase further, because many invasive species are expanding their distribution ranges and new species are being established as a result of the global trade.

Second, future changes in climatic conditions will heavily affect the distribution of many plant resources. Given the current scattering of small nature reserves in the eastern and highly diverse southern regions of China and the lack of migration corridors between reserves, many rare plant species and species with limited distribution ranges and dispersal abilities face a severe threat of extinction.

To successfully safeguard the future of China's plant resources, we therefore suggest the following seven strategic steps:

Step 1. The efficient conservation of Chinese plant resources first of all requires accurate data on the current distribution and threat status of plant species in the country. Presently, even most protected-area administrations are unsure about the status of the resources they are charged with protecting. A vital step to address this situation is a detailed survey of the distribution and population sizes of plant resources throughout China. There are already a number of activities addressing the problem. These include the Flora of China project (http://hua.huh.harvard.edu/china), which is cosupported by the Chinese Academy of Sciences and the National Science Foundation of China. The project was started in 1989, and the resulting series of books (Wu Z-Y and Raven 1990-2009, Wu Z-Y et al. 1990-2010) is jointly edited by botanists from China and America. The series is based partly on a translation of the Chinese edition of the Flora of China (Editorial Board of the Flora of China 1959-2004) but this version is updated and extended (Li D 
and Huang 2006), aiming to provide a thorough overview of plant species in China. In collaboration with eight additional agencies and with financial support from the Ministry of Finance, the Ministry of Environment Protection also set up the China Important Species Survey Project in 2004, with the goal of establishing the distribution and state of economically and environmentally important species and their habitats (Xue 2005). These projects need to be sustained and further developed to create a solid knowledge platform, with in-depth inventories covering all protected areas, as well as all rare and endangered species.

Step 2. On the basis of the survey results, specific management and monitoring plans for all protected areas and threatened plant species need to be developed and strictly enforced. Monitoring of threatened species needs to include not only in situ activities, but also the development of a more effective warning and monitoring system for illegal trade and further control measures for the export of rare, threatened plant species, such as wild orchids, and rare medicinal plants. Such a system will need to cover airports but also ports and terrestrial borders. Current supervision and management of trade in natural resources that are legally protected is lacking, particularly at marine ports and terrestrial borders (Beyer 2006). It is also important that such measures are balanced in controlling trade, while still allowing scientific exchange and progress.

A strengthening of control measures is also needed for biological resources entering China-namely, to guard the country against the introduction of invasive plant and animal species, as well as of harmful pathogens. The current lack of sufficient control measures has already created threats to biodiversity (Jiang $\mathrm{Z}$ and Xie 2008) and great economic losses to farmers, and has even had direct effects on people's health (Sun et al. 2002). We therefore call for an integrated, high-level monitoring network using both measures for an effective control of biological material leaving and entering China and regular reports on the status of and threats to natural resources within the country. These should be based on a regular, detailed monitoring scheme conducted throughout the country to assess habitat conditions. Such a survey system would also allow us to obtain vital information on the spread of invasive species and harmful pathogens, which forms a prerequisite for the development of suitable control measures (SEPA 2007). All of these activities must be accompanied by efficient legislation and management structures, as well as by sufficient funding. Best-practice models need to be developed or identified and implemented throughout China (SEPA 2007).

Step 3. The strong bias in the spatial distribution of nature reserves must be addressed, and the existing reserve network needs to be adjusted on the basis of the distribution of endemic species, threatened species, and overall phytodiversity. Nature reserves also need to be better connected in order to allow migration in reaction to climate change (Corlett 2009). For this network to fulfill its role, supporting nature conservation legislation needs to be enacted and enforced in a timely and effective manner, and in the meantime, a series of practical regulations and technical-planning standards need to be put into force. Furthermore, the current state development plans for nature reserves for the period of 2006-2020 (Xue 2005) needs to be further developed in order to support the construction of such protected-area networks throughout the entire country. The exploitation of resources in protected areas and their use in the tourism trade needs to be strictly regulated and controlled, with sustainable concepts for ecotourism taking precedence over large-scale tourism projects aimed at generating mass tourism. Planning models and guidelines not only for the designation but also for the day-to-day management of nature conservation areas and the monitoring of their resources need to be developed and applied throughout the country.

Apart from nature reserves, a wide range of additional protected areas already exists, including, for example, scenic spots and forest or wetland parks. There are more than 1000 scenic spots and 2000 forest parks distributed throughout China, accounting for more than $1 \%$ of the country's land area (Jiang M-K et al. 2006). Because many of these protected areas are located in regions harboring high levels of phytodiversity, they could complement the nature reserve networks. However, as they are currently regarded primarily as places for human enjoyment and tourism development, a strong shift in perception is needed in order to achieve widespread recognition of their inherent value in biodiversity conservation.

Step 4. Throughout China, economic progress and the well-being of its people are the main driving power behind new developments. The advantages of the protection and sustainable use of natural resources for the common wealth and well-being must therefore be emphasized more clearly, and factors adversely affecting protected areas, such as unsustainable levels of tourism, tourism infrastructure, encroachment, and mining, need to be addressed more coherently to shift priorities from short-term economic gain to long-term resource utilization and protection. Concepts of sustainable ecotourism that provides new income streams to local communities in exchange for a more sustainable utilization of their natural resources need to be adapted to the socioeconomic setting of China (Li W 2004).

Step 5. Conflicts between the interests of rural communities and nature conservation need to be resolved. With increasing urbanization, most young people are leaving remote rural areas to get a better education or work in the cities (Zhang K-H and Song 2003). Large sections of the remaining, aging population would welcome a move into modern flats in urban areas if appropriate government incentives were provided. Such developments would greatly decrease the pressure on overexploited natural resources in the wider 
vicinity of the numerous scattered rural villages and would concentrate anthropogenic pressure mainly in fewer, larger cities. Government programs addressing this issue have already been started-for example, by the government's encouragement of and paying for the transformation of farmland areas into forest or grassland ecosystems (Li W 2004) or by current resettlement plans for the rural populations living in remote villages in Jilin Province in areas near the Russian border (Feng and Xia 2007). It needs to be acknowledged that urbanization itself creates a wealth of problems - for example, increased pollution levels, the spreading of urbanized areas, and the creation of areas of high concentrations of invasive species (McKinney 2002). Nevertheless, it is worth mentioning that Chinese cities tend to concentrate their populations strongly within the city centers (Zhu and Lin 2004), limiting the urban sprawl typical of many cities-for example, in the United States. Furthermore, a large number of exotic plant species are already commonly grown in Chinese rural villages (Sang 2003, Wan et al. 2009), which leaves numerous sites from which these species could easily establish themselves as invaders in highly sensitive natural habitats.

In our view, the advantages of a planned and steered increase in urbanization aimed at the abandonment of remote rural villages in ecologically sensitive areas will therefore outweigh the potential problems. Nonetheless, the environmental impact of such measures needs to be minimized, and advances in sustainable urban planning (Zhu and Lin 2004) should be strongly encouraged in the respective initiatives. Furthermore, it is important to increase the awareness and appreciation within the remaining rural population of more sustainable levels of natural resource use. This requires an increased emphasis on environmental education, aimed particularly at the older people typically inhabiting the remote rural settlements.

Step 6. Temporary ex situ protection of very rare and threatened species should also be considered, and botanical gardens should be strongly encouraged to develop the necessary infrastructure and scientific skills for a stronger emphasis on preserving China's phytodiversity. There are already more than 140 botanical gardens distributed throughout China (Xue 2005). Unfortunately, their current contribution to the preservation of China's phytodiversity is limited, because only a relatively small proportion of threatened and rare species are currently cultivated in botanical gardens. Most of the botanical gardens are also located outside of phytodiversity hotspots and only cover small areas, which further limits their ability to serve as temporary refuges for China's threatened phytodiversity (López-Pujol et al. 2006). Some protected areas also harbor small botanical gardens or collections as showcases of their plant resources, with plants on display often collected from the wild and cultivated under unsuitable conditions, so that they wilt and have to be replaced regularly with additional wild specimens (SEPA 2007). Such practices obviously have to be strongly discouraged. A long-term strategy for plant conservation in botanical gardens is required, including the creation or extension of four to six large botanical gardens and arboretums in different climatic regions of China with a clear focus on the ex situ conservation of China's phytodiversity (Chen et al. 2009).

Step 7. Overall, there is a strong need for enhanced funding, training, and capacity building in traditional taxonomy, experimental ecosystem laboratories, and ecosystem management. These skills are of great importance to provide the specialist knowledge needed for conservation work at all levels (Li W 2004, López-Pujol et al. 2006).

\section{Acknowledgments}

We thank Katherine Bowers, Wenbin Guan, Jihong Huang, Liqiang Ji, Jingwen Li, Zhaohua Lu, Shunzhong Wang, Jian Zhang, Yinghui Zhang, and three anonymous reviewers for their comments on the manuscript. We also thank the Ministry of Science and Technology for the key basic research and development program (Grant 2010CB951301-6), scientific supporting project of the Ministry of Science and Technology (Grant 2008BAC39B02-03), the China Bureau of Foreign Experts and the Ministry of Education of China (111 Program, Grant 2008-B08044), and the Chinese Academy of Sciencess' Fellowship for Young International Scientists (Fellowship Number 2010Y1SA16), for their financial support.

\section{References cited}

Beyer S. 2006. Environmental law and policy in the People's Republic of China. Chinese Journal of International Law 5: 185-211.

Butchart SHM, et al. 2010. Global biodiversity: Indicators of recent declines. Science 328: 1164-1168.

Cantú-Salazar L, Gaston KJ. 2010. Very large protected areas and their contribution to terrestrial biological conservation. BioScience 60: 808-818.

Cao S, Wang G, Chen L. 2010. Questionable value of planting thirsty trees in dry regions. Nature 465: 31.

Chen J, Cannon C-H, Hu H. 2009.Tropical botanical gardens: At the in situ ecosystem management frontier. Trends in Plant Science 14: 584-589.

Corlett RT. 2009. Seed dispersal distances and plant migration potential in tropical East Asia. Biotropica 41: 592-598.

Ding J, Mack RN, Lu P, Ren M, Huang H. 2008. China's booming economy is sparking and accelerating biological invasions. BioScience 58: 317-324.

Editorial Board of the Flora of China. 1959-2004. Flora of China, vols. 1-80. Beijing Science Press.

Feng J, Xia Z. 2007. A review of the poverty in forest regions in china and the solution approaches. Journal of the Beijing Forestry University (Social Sciences) 6: 63-67.

Han N. 2000. A policy study on sustainable management for China's nature reserves. Journal of Natural Resources 15: 201-207.

Han N, Ren Z. 2001. Ecotourism in China's nature reserves: Opportunities and challenges. Journal of Sustainable Tourism 9: 228-242.

Harkness J. 1998. Recent trends in forestry and conservation of biodiversity in China. China Quarterly 156: 911-934.

Hu Y, Zhang Y, Qin H, Liu Y, Yu M. 2009. The in situ conservation of state key protected wild plants in national nature reserves in China. Biodiversity Science 17: 280-287.

Jiang M-K, Wang Z, Qin W-H, He Z-H. 2006. Effectiveness of national priority wildlife protection in nature reserves. Journal of Ecology and Rural Environment 22: 35-38.

Jiang Z, Xie Z. 2008. Species Protection. China Forestry Publishing House. 
Jim CY, Xu SSW. 2004. Recent protected-area designation in China: An evaluation of administrative and statutory procedures. Geographical Journal 170: 39-50.

Li D, Huang L. 2006. The newest progress on the English version of the "Flora of China." Yunnan Botanical Research 283: 314-326.

Li M, Xu H. 2005. Evaluation of economic loss of biological invasion on species and gene. Journal of the Nanjing Forestry University (Natural Science Version) 29: 98-102.

Li W. 2004. Degradation and restoration of forest ecosystems in China. Forest Ecology and Management 201: 33-41.

Liu J, Diamond J. 2005. China's environment in a globalizing world. Nature 435: 1179-1186.

Liu J, Ouyang Z, Pimm SL, Raven PH, Wang X, Miao H, Han N. 2003. Protecting China's Biodiversity. Science 300: 1240-1241.

López-Pujol J, Zhang F-M, Ge S. 2006. Plant biodiversity in China: richly varied, endangered, and in need of conservation. Biodiversity and Conservation 15: 3983-4026.

McKinney ML. 2002. Urbanization, biodiversity, and conservation. BioScience 52: 883-890.

Mittermeier RA, Gil PR, Hoffman M, Pilgrim J, Brooks T, Mittermeier CG, Lamoreux J, da Fonseca GAB. 2005. Hotspots Revisited: Earth's Biologically Richest and Most Endangered Terrestrial Ecoregions. Conservation International.

Normile D. 2008. China's living laboratory in urbanization. Science 319: $740-743$.

Peng J, Wang Y, Liu S, Wu J, Li W. 2004. Research on landscape ecology and sustainable land use. Acta Scientia Naturalis Universitis Pekinensis 40: 154-160.

Purugganan MD, Fuller DQ. 2009. The nature of selection during plant domestication. Nature 457: 843-848.

Rozelle S, Huang J, Zhang L. 1997. Poverty, population and environmental degradation in China. Food Policy 22: 229-251.

Sang W. 2003. The invasive characteristics analysis of alien grasses in China. Journal of Agricultural Science and Technology 4: 59-61.

[SEPA] State Environmental Protection Administration of China. 1998. China's Biodiversity: A Country Study. China Environmental Science Press.

. 2007. Planning Compendium of Biology Resource Conservation and Utilization in China. SEPA.

Stone R. 2009. Nursing China's ailing forests back to health. Science 325: $556-558$.
Sun JH, Yuan DC, Ouyang H. 2002. Exotic forest pest invasion: A threat to forest ecosystems in China. Forest Pest and Disease 6: 32-35.

Wan F, Guo J, Zhang F. 2009. Research on Biological Invasions in China. Science Press.

Wang G, Innes JL, Lei J, Dai S, Wu SW. 2007. China's forestry reforms. Science 318: 1556-1557.

Weber E, Li B. 2008. Plant invasions in China: What is to be expected in the wake of economic development? BioScience 58: 437-444.

Williams R. 2005. WWF warns that China's forests are not out of the woods. Nature 434: 459.

Wu X. 1992. Brief Compilation of Chinese Medical Plants. Guangdong Higher Education Publishing.

Wu Z-Y, Raven PH. 1990-2009. Flora of China, vols. 1, 80. Science Press and Missouri Botanical Garden.

Wu Z-Y, Raven PH, Hong DY. 1990-2010. Flora of China, vols. 1, 80. Science Press and Missouri Botanical Garden.

Xue D. 2005. Status quo and protection of bio-genetic resources in China. China Environmental Sciences Press.

Xu H, Tang X, Liu J, Ding H, Wu J, Zhang M, Yang Q, Cai L, Zhao H, Liu Y. 2009. China's progress toward the significant reduction of the rate of biodiversity loss. BioScience 59: 843-852.

Ying J, Zhang Y. 1994. Endemic genera of seed plant species in China. Science Press.

Yu X. 2010. Biodiversity conservation in China: Barriers and future actions. International Journal of Environmental Studies 67: 117-126.

Zhang K-H, Song S. 2003. Rural-urban migration and urbanization in China: Evidence from time-series and cross-section analyses. China Economic Review 14: 386-400.

Zhang Y-B, Ma K-P. 2008. Geographic distribution patterns and status assessment of threatened plants in China. Biodiversity and Conservation 17: 1783-1798.

Zhou Z, Jiang Z. 2004. Dynamics of the International Trade in Wild Fauna and Flora in China. Scientia Silvae Sinicae 40: 151-156.

Zhu Y, Lin B. 2004. Sustainable housing and urban construction in China. Energy and Buildings 36: 1287-1297.

Weiguo Sang (swg@ibcas.ac.cn) and Keping Ma are affiliated with the State Key Laboratory of Vegetation and Environmental Change, at the Institute of Botany, in the Chinese Academy of Sciences, Beijing. Jan C. Axmacher is affiliated with the Department of Geography, at University College, London, United Kingdom. 